\title{
Women remain underrepresented in leadership positions in academic gastroenterology throughout the United States
}

\author{
Daniel S. Jamorabo a, Richy Chen ${ }^{b}$, Hashroop Gurmc, Muntasir Jahangird, William M. Briggse, \\ Smruti R. Mohanty ${ }^{b}$, Benjamin D. Renelus ${ }^{f}$
}

Stony Brook Medicine, Stony Brook, NY; New York-Presbyterian Brooklyn Methodist Hospital, Brooklyn, NY; University of Oklahoma College of Medicine, Oklahoma City, OK; Memorial Hermann Hospital, Houston, TX; Morehouse School of Medicine, Atlanta, GA, USA

\section{Abstract}

${ }^{a}$ Division of Gastroenterology and Hepatology, Stony Brook

Medicine, Stony Brook, NY (Daniel S. Jamorabo); bepartment of Gastroenterology and Hepatology, New York-Presbyterian Brooklyn Methodist Hospital, Brooklyn, NY (Richy Chen, Smruti R. Mohanty); 'Division of Gastroenterology and Hepatology, University of Oklahoma College of Medicine, Oklahoma City, OK (Hashroop Gurm);

dDepartment of Internal Medicine, Memorial Hermann Hospital, Houston, TX (Muntasir Jahangir); ${ }^{\mathrm{e}}$ Department of Biostatistics, New York-Presbyterian Brooklyn Methodist Hospital, Brooklyn, NY (William

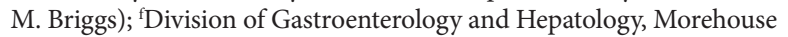
School of Medicine, Atlanta, GA (Benjamin D. Renelus), USA

\section{Conflict of Interest: None}

Correspondence to: Daniel S. Jamorabo, MD, Division of Gastroenterology and Hepatology, 101 Nicolls Road, HSC T17-060, Stony Brook, NY 11794, USA,

e-mail: Daniel.Jamorabo@stonybrookmedicine.edu

Received 29 July 2020; accepted 6 December 2020; published online 5 February 2021

DOI: https://doi.org/10.20524/aog.2021.0597

\section{Introduction}

Despite a steady, relatively recent increase in female matriculants to medical school and residency training programs, women have been underrepresented on medical journal boards [1], in publications in high-level specialty journals [2], and in research trials [3]. Throughout their medical careers, female researchers are more likely to receive lower salaries than men, and they are also less likely to report successful sponsorship for both National Institute of Health grants and long-term academic success, as gauged by appointment to senior administrative positions, grant rewards, and publications [4,5]. Even with equal access to funding, disparities in publication persist. This was evidenced in a longitudinal analysis of 1244 medical school faculty members, showing that despite equivalent rates of federal funding for men and women, the latter still had lower Hirsch (h) indices and total publications for unclear reasons [6]. 
Gastroenterology (GI) has become one of the more competitive adult medicine subspecialties in recent years and, as in other fields, academic productivity as measured by publication quantity and quality is a key factor in promotion. Our working hypothesis was that women are underrepresented in academic GI leadership positions and in subspecialties of GI, despite having similar markers of publication productivity and career lengths to their male peers. To investigate our hypothesis, we looked at GI programs in the United States (US) to determine sex representation amongst fellowship program directors (PDs), division and department chiefs and chairs, and GI subspecialists, and also to determine trends in publication history and quality as measured by the h-index $[7,8]$.

\section{Materials and methods}

This was a cross-sectional study that included faculty and trainee names, h-indices, and year of first GI certification gathered from 1 February 2020 through 1 March 2020. This was to ensure that all h-indices and year of first GI certification were updated through the end of 2019. Similarly, time in practice was calculated from the year of first certification through 2019. Our outcome of interest was mean difference in h-index between men and women, based on geography, faculty position, trainee status, advanced degree, documented subspecialty and year of first certification in GI. Though we focused mainly on GI faculty, we included trainees in our study to determine sex representation throughout the full spectrum of GI academia.

We gathered the names of PDs and their program locations and sizes from the Accreditation Council for Graduate Medical Education website. We identified trainees and other faculty on the program websites and gathered information on who had listed subspecialties, specifically advanced endoscopy, pancreatology, transplant hepatology, motility, and inflammatory bowel disease. We also used program sites and Google searches to confirm sex and to determine whether any faculty member was also listed as a division chief or chair and advanced degree holder. The geographic regions-Northeast, West, South, Midwest, and Puerto Rico-were those defined by the US Census Bureau $[1,9]$.

The American Board of Internal Medicine website provided the year of first certification in GI and, if applicable, transplant hepatology. This information was used to determine approximate years in practice. In the US, clinical training to become an adult gastroenterologist involves completing 3 years of adult internal medicine residency along with a board certification test, followed by three years of general GI fellowship training, at the end of which the trainee takes a GI board certification exam. After completing a GI fellowship, trainees can pursue further sub-specialization with one year of transplant hepatology - followed by a transplant hepatology board certification exam-or 1-year fellowships in motility, advanced endoscopy and inflammatory bowel disease. Pancreatology can overlap with advanced endoscopy, but is sometimes its own subspecialty, so we analyzed it separately from advanced endoscopy. We used Scopus to determine each person's h-index and total number of publications for 2019. We chose this server over Google Scholar, Web of Science and others because it limits publications to full-length peerreviewed manuscripts [10].

Given the lack of uniform reporting on program websites, we did not gather information on professor ranking, trainee level or race. We divided faculty into those listed as Chair/ Chief and PD simultaneously, Chair/Chief without PD title, PD without Chair/Chief title, and "other" faculty. We excluded faculty members and PDs for whom we could not confirm their year of first GI certification. We also removed anybody who had multiple or no listed accounts on Scopus, since their $\mathrm{h}$-indices and listed publications could not be definitively verified. Preliminary data were collected from 1 February 2018 through 1 May 2018, then updated from 1 February 2020 through 1 March 2020. Our final cohort included 3655 people, specifically 289 PDs and division chiefs/chairs, 2657 faculty, and 998 trainees.

The New York-Presbyterian Institutional Review Board approved the study (IRB \#1157038-1).

\section{Statistical analysis}

Univariate regression modeling with $t$-testing was used to estimate the mean difference in h-index between men and women by academic position, listed subspecialty, year of first GI certification and geography. Multivariate analysis controlling for sex and year of first certification allowed us to calculate the mean difference in h-index and total publications between men and women. All analyses were done using $\mathrm{R}$ Version 3.4.2 (R Core Team 2017, Vienna, Austria).

\section{Results}

\section{Baseline characteristics}

We included a total of 3655 faculty members and trainees across 163 academic GI programs in the US. This included 1049 women $(28.7 \%)$, of whom $713(68.0 \%)$ were faculty and $336(32.0 \%)$ were fellows as of the end of 2019. The proportions of women and men were equivalent by geographic region and advanced degree holders, but men were significantly overrepresented among all faculty (1944/2657; 73.2\%), trainees $(662 / 998 ; 66.3 \%)$, and documented subspecialties (Table 1). The cohort's baseline characteristics are summarized in Table 1.

Overall, 56/713 (7.9\%) female faculty members were in leadership positions compared to $233 / 2606$ (8.9\%) of male faculty members. Of the 289 faculty in leadership positions, women comprised just 19.4\% (56/289). Women likewise made up $16.8 \%(24 / 143)$ of the listed chairs/chiefs and $22.7 \%$ (37/163) of the PDs. Among documented subspecialists, 
Table 1 Baseline characteristics

\begin{tabular}{|c|c|c|c|c|c|c|}
\hline \multirow[t]{2}{*}{ Variables } & & \multicolumn{2}{|c|}{ Women } & \multicolumn{2}{|c|}{ Men } & \multirow{2}{*}{$\begin{array}{c}\text { P-value } \\
\text { (chi-squared analysis) }\end{array}$} \\
\hline & & $\begin{array}{l}\text { Number } \\
(\mathrm{n}=1049)\end{array}$ & $\begin{array}{l}\text { Percent } \\
(\%)\end{array}$ & $\begin{array}{l}\text { Number } \\
(\mathrm{n}=2606)\end{array}$ & $\begin{array}{l}\text { Percent } \\
(\%)\end{array}$ & \\
\hline \multirow[t]{5}{*}{ Region } & Puerto Rico & 4 & 0.381 & 7 & 0.3 & 0.23 \\
\hline & Midwest & 221 & 21.1 & 634 & 24.3 & \\
\hline & Northeast & 363 & 34.6 & 866 & 33.2 & \\
\hline & South & 277 & 26.4 & 689 & 26.4 & \\
\hline & West & 184 & 17.5 & 410 & 15.7 & \\
\hline \multirow[t]{2}{*}{ Grouping } & Faculty & 713 & 68 & 1944 & 74.6 & $<0.001$ \\
\hline & Trainee & 336 & 32 & 662 & 25.4 & \\
\hline \multirow[t]{5}{*}{ Academic Position } & Chair/Chief only & 19 & 1.81 & 107 & 4.1 & $<0.001$ \\
\hline & Chair/Chief AND program director & 5 & 0.5 & 12 & 0.5 & \\
\hline & Program director only & 32 & 3.1 & 114 & 4.4 & \\
\hline & Other faculty & 657 & 62.6 & 1711 & 65.7 & \\
\hline & Fellow & 336 & 32 & 662 & 25.4 & \\
\hline \multirow[t]{4}{*}{ Advanced Degree? } & MBA & 0 & 0 & 2 & 1.3 & 0.38 \\
\hline & MPH & 10 & 20.8 & 19 & 12.1 & \\
\hline & MSPH & 1 & 2.1 & 2 & 1.3 & \\
\hline & $\mathrm{PhD}$ & 37 & 77.1 & 134 & 85.4 & \\
\hline \multirow[t]{5}{*}{ Documented Subspecialty } & Advanced Endoscopy & 35 & 3.3 & 238 & 9.1 & $<0.001$ \\
\hline & Transplant Hepatology (Certified) & 149 & 14.2 & 354 & 13.6 & \\
\hline & Inflammatory bowel disease & 82 & 7.8 & 163 & 6.3 & \\
\hline & Motility & 38 & 3.6 & 73 & 2.8 & \\
\hline & Pancreatology & 6 & 0.6 & 34 & 1.3 & \\
\hline
\end{tabular}

women comprised 149/504 certified transplant hepatologists (29.6\%) and 35/273 (12.8\%) of advanced endoscopists.

\section{h-Index comparisons}

When comparing h-indices for men and women by geographic region, men overall have mean h-indices roughly twice those of women, except for the Puerto Rican institutions. Similar differences arise between men and women listed as division chairs or chiefs, PDs, other faculty, advanced degree holders, and subspecialists, though fellows have roughly similar mean h-indices ( 0.8 for women vs. 1.2 for men). Our findings are presented in Table 2.

\section{h-Index comparisons by decade}

Male faculty overall had higher mean h-index compared to women ( 11.4 vs. $5.5, \mathrm{P}<0.001)$, a statistically significant difference. On multivariate analysis taking account of year of first GI certification, men's mean h-index was 2.8 higher (95\% confidence interval [CI] 1.3-4.1) compared to women's; this difference was also statistically significant $(\mathrm{P}<0.001)$. This gap was evident and consistent from the 1980s through the 2010s. The gap was especially large in the 1950-1970s group, in which we found no women certified until 1972. Our multivariate analysis also found that men had 14.5 more publications $(95 \%$ CI $7.8-21.2, \mathrm{P}<0.001)$ than women, when adjusted for year of first GI certification. The h-index comparisons are depicted in Table 3.

\section{Comparing career length and publications for faculty}

Among all GI faculty, women tended to have been first certified more recently than men $(2010$ vs. $2000, \mathrm{P}<0.001)$, thereby implying a shorter career length overall compared to men. We also found that, overall, women had lower h-indices (5.5 vs. 11.4) and numbers of publications (15.6 vs. 41.9) compared to their male peers, both differences being statistically significant $(\mathrm{P}<0.001)$. On our subset analysis of the 289 division chairs, chiefs and PDs, women and men were certified at about the same time (2000), suggestive of similar career lengths, though men had a statistically significantly higher mean h-index compared to women (17.8 vs. 10.4, $\mathrm{P}=0.005)$. Our comparisons are documented in Table 4. 
Table 2 Hirsch index comparisons

\begin{tabular}{|c|c|c|c|c|c|c|c|c|c|}
\hline \multirow[t]{2}{*}{ Variables } & & \multicolumn{4}{|c|}{ Women $(n=1049)$} & \multicolumn{4}{|c|}{ Men $(n=2606)$} \\
\hline & & Median & Mean & $\begin{array}{l}\text { Standard } \\
\text { deviation }\end{array}$ & $\begin{array}{l}\text { P-value } \\
(t \text {-test })\end{array}$ & Median & Mean & $\begin{array}{l}\text { Standard } \\
\text { deviation }\end{array}$ & $\begin{array}{l}\text { P-value } \\
(t \text {-test })\end{array}$ \\
\hline \multirow[t]{5}{*}{ Region } & Puerto Rico & 0 & 1.8 & 3.5 & 0.02 & 0 & 0.7 & 1.3 & $<0.001$ \\
\hline & Midwest & 2 & 6.4 & 11.2 & & 4 & 11.7 & 16.7 & \\
\hline & Northeast & 2 & 4.2 & 8.1 & & 3 & 9.7 & 15.4 & \\
\hline & South & 2 & 5.6 & 10.6 & & 3 & 11.8 & 17.9 & \\
\hline & West & 2.5 & 6.8 & 11.1 & & 6 & 14 & 18.9 & \\
\hline \multirow[t]{5}{*}{ Academic rank } & Chair/Chief only & 8 & 11.1 & 10.2 & $<0.001$ & 19 & 23.4 & 20.3 & $<0.001$ \\
\hline & Chair/Chief AND program director & 6 & 6.4 & 4.7 & & 8 & 12.1 & 15 & \\
\hline & Program director only & 6 & 10.6 & 13.7 & & 6 & 13.1 & 15.5 & \\
\hline & Other faculty & 4 & 7.4 & 11.5 & & 6 & 14.5 & 18.4 & \\
\hline & Fellow & 0 & 0.8 & 1.6 & & 0 & 1.2 & 2.5 & \\
\hline \multirow[t]{4}{*}{ Advanced Degree Holder } & MBA & NA & NA & NA & 0.81 & 37 & 37 & 52.3 & 0.02 \\
\hline & $\mathrm{MPH}$ & 0.5 & 8.6 & 18.8 & & 5 & 7.5 & 7.9 & \\
\hline & MSPH & 4 & 4 & NA & & 3 & 3 & 0 & \\
\hline & $\mathrm{PhD}$ & 5 & 11.3 & 14.2 & & 12 & 18.2 & 18.4 & \\
\hline \multirow{5}{*}{$\begin{array}{l}\text { Documented } \\
\text { Subspecialty }\end{array}$} & Advanced endoscopy & 5 & 9.1 & 12.2 & $<0.001$ & 9 & 14.2 & 14.9 & $<0.001$ \\
\hline & Transplant hepatology (Certified) & 5 & 10.2 & 14.1 & & 13 & 20.7 & 21.2 & \\
\hline & Inflammatory bowel disease & 4.5 & 7.6 & 9.6 & & 10 & 18.3 & 21.2 & \\
\hline & Motility & 3.5 & 5.7 & 6.7 & & 20 & 22.3 & 21.2 & \\
\hline & Pancreatology & 7.5 & 11.8 & 12.8 & & 22 & 25.4 & 22.3 & \\
\hline
\end{tabular}

Table 3 Hirsch index comparisons by decade

\begin{tabular}{|c|c|c|c|c|c|c|c|}
\hline \multirow[t]{2}{*}{ Year of first gastroenterology certification } & \multicolumn{3}{|c|}{ Women $(n=713)$} & \multicolumn{3}{|c|}{ Men $(n=1944)$} & \multirow[t]{2}{*}{ P-value $(t$-test $)$} \\
\hline & Median & Mean & Standard deviation & Median & Mean & Standard deviation & \\
\hline $1950-1970 s$ & 12.5 & 10.7 & 5.9 & 14 & 22.4 & 22.8 & $<0.001$ \\
\hline $1980 \mathrm{~s}$ & 10 & 18.6 & 25 & 11 & 20.9 & 23.2 & \\
\hline $1990 \mathrm{~s}$ & 8 & 14.7 & 16.2 & 17 & 20.8 & 20.6 & \\
\hline 2000 s & 5 & 9.2 & 9.9 & 9 & 11.9 & 11.4 & \\
\hline 2010s & 3 & 3.5 & 3.8 & 3 & 4.8 & 5.9 & \\
\hline Overall & 2 & 5.5 & 10.1 & 4 & 11.4 & 17 & $<0.001$ \\
\hline
\end{tabular}

\section{Discussion}

We were able to evaluate a large cross-section of GI programs in the US and focus on sex representation in leadership positions and within particular subspecialties, using data through 2019. Though we found a trend toward more equal representation between men and women among more recent graduates and among trainees, women overall remain underrepresented among PDs, division and department chairs or chiefs, and other faculty as a whole.

Notably, the proportion of female faculty in leadership positions $(56 / 713 ; 7.9 \%)$ was about equal to that of male faculty $(233 / 2606 ; 8.9 \%)$, which could imply that women are being promoted at similar rates to their male counterparts. Indeed, we had found that male and female division chairs, chiefs and PDs had similar career lengths-about 19 yearsas reflected by year of first GI certification (2000). If women join GI ranks in increasing numbers and if promotion rates remain equal, then women should theoretically make up a larger share of leadership positions in the near future. The sex imbalance nonetheless persists at the faculty level, where women comprised about one-fourth (713/2657; 26.8\%), and in leadership positions, where women held one-fifth of spots (56/289; 19.4\%). 
Table 4 Comparing career length and publications for gastroenterology (GI) faculty

\begin{tabular}{|c|c|c|c|c|c|c|c|c|}
\hline \multirow[t]{2}{*}{ Variables } & & \multicolumn{3}{|c|}{ Women } & \multicolumn{3}{|c|}{ Men } & \multirow{2}{*}{$\begin{array}{l}\text { P-value } \\
(t \text {-test })\end{array}$} \\
\hline & & Median & Mean & Standard deviation & Median & Mean & Standard deviation & \\
\hline \multirow{3}{*}{$\begin{array}{l}\text { All GI faculty } \\
(\mathrm{n}=2657)\end{array}$} & Year of first GI certification & 2010 & 2010 & 9.0 & 2000 & 2000 & 12.6 & $<0.001$ \\
\hline & Hirsch index & 2 & 5.5 & 10.1 & 4 & 11.4 & 17.0 & $<0.001$ \\
\hline & Total number of publications & 3 & 15.6 & 37.9 & 7 & 41.9 & 80.4 & $<0.001$ \\
\hline \multirow{3}{*}{$\begin{array}{l}\text { Chair/Chief } \\
\text { and/or program } \\
\text { directors }(n=289)\end{array}$} & Year of first GI certification & 2000 & 2000 & 7.4 & 2000 & 2000 & 10.4 & 1 \\
\hline & Hirsch index & 6.5 & 10.4 & 12.0 & 10 & 17.8 & 18.5 & 0.005 \\
\hline & Total number of publications & 15 & 30.8 & 44.4 & 28 & 69 & 100.0 & 0.006 \\
\hline
\end{tabular}

This lack of female visibility can have an impact on attracting female applicants to training programs, thereby perpetuating further underrepresentation. A recent study noted that at least $43 \%(74 / 173)$ of US GI fellowship programs had no women as chairs, division chiefs, PDs or associate PDs, and that the presence of either a female PD or associate PD was associated with a greater proportion of female fellows ( 4.0 women vs. 3.2 men, $\mathrm{P}=0.08$; and 4.3 vs. 3.4 men, $\mathrm{P}=0.04$, respectively) [11]. Another survey of 125 GI division chiefs, PDs and leaders from the American Society of Gastrointestinal Endoscopy highlighted the lack of female mentorship for women, with women more likely than men to report wanting to have a samesex mentor $(60 \%$ vs. $25 \%, \mathrm{P}<0.001)$, though only $4 \%$ of all respondents had a sole female mentor [12]. The same authors found that female GI leaders were more likely than men to have had a promotion within 6 years of finishing training ( $81 \%$ vs. $62 \%, \mathrm{P}=0.05)$ and they did not remain childless or otherwise delay having children compared to male peers, yet women still felt they were treated differently by patients and underpaid ( $73 \%$ vs. $13 \%, \mathrm{P}<0.001$ ).

Our view is that the lack of female mentor and leader figures has wide-ranging consequences, in particular that female trainees may perceive that colleagues and faculty have lower expectations about endoscopic skill, competence and work ethic [13], and these may then lead some women to leave academia altogether to work elsewhere [14]. Indeed, a recent survey of 210 gastroenterologists in private practice and in academic programs found that female respondents were less likely than men to have a current leadership role ( $36 \%$ vs. $52 \%$, $\mathrm{P}=0.03$ ) [15]. Of note, when the authors looked specifically at respondents who had completed their training within 5 years of the survey, more women than men were in leadership positions ( $25 \%$ vs. $6 \%)$, though there was no statistically significant difference $(\mathrm{P}=0.11)$. The difference between their findings and ours may be due to their smaller sample size and possibly to leadership openings in non-academic settings. Jagsi et al noted that, among elite early-career physicians, women remained underpaid compared to men after adjustment for specialty, academic rank, work hours and research time [16]. Even with leadership positions available [17], a considerable number of women may still feel that they must work harder than their male peers, whether they reach the same benchmarks for success or fall short [18]. Long et al observed that, while the percentage of female authors of original research in major GI journals increased over 20 years, the percentage of women listed as senior authors remained low [19].

This finding may be connected with our own finding on multivariate analysis that men have a higher h-index and total number of publications, even after adjustment for year of first GI certification and for seniority. Our findings differ from those of our colleagues Diamond et al, whose cross-sectional study in 2014 of 2440 faculty in 114 GI programs found that $\mathrm{h}$-indices and publications were equivalent for male and female faculty, even in senior positions. We ascribe these discrepancies to our moderately larger sample numbers of people $(n=2657)$ and programs $(n=163)$, in addition to our use of the year of first GI certification to establish the start of an academic GI career, whereas their study used year of first publication to determine career duration. We also simplified our definition of leadership positions to include only division or departmental chairs/ chiefs and fellowship PDs. Professor ranking was outside the scope of our study, because we did not have a reliable way to verify this. In our study, women in leadership positions had lower mean h-indices and total publications, despite similar career length as gauged by mean year of first GI certification. Part of this may simply reflect different career goals that are not captured by bibliographic measures, for instance involvement in committees, administration, and educational activities that can factor into leadership consideration $[20,21]$. Elsewhere in academic medicine, researchers have noted similar patterns of sex disparities in leadership positions and faculty retention [14,22], in training programs [23], and in salaries [24], so our findings are consistent with those noted broadly in academic medicine. Apart from career goals, women are more likely than men to face workplace hostility [25], gender bias [26], lack of mentorship or research funding [27,28], unfair pay structures $[5,29]$, greater expectations for parenting and domestic responsibilities [30], and inadequate parental leave policies [31], all of which can negatively impact research productivity.

Mentoring from early career stages is especially important, since h-indices favor researchers with longer careers, whose studies have had a chance to circulate and accrue citations. Mentorship is also vital to facilitate junior faculty members' successful pursuit of research grants, which can then lead to publications, promotions and job satisfaction $[28,32,33]$. A lack of mentorship could dissuade women from pursuing certain subspecialties within GI, for instance advanced endoscopy, 
where $4.9 \%$ (35/713) of female faculty are specialized compared to $12.2 \%(238 / 1944)$ of male faculty, in contrast to transplant hepatology $(149 / 713,20.9 \%$ of female faculty vs. 354/1944, $18.2 \%$ of male faculty) or inflammatory bowel disease (82/713, $11.5 \%$ of female faculty vs. $163 / 1944,8.4 \%$ of male faculty). Our view is that more women would be encouraged to become advanced endoscopists if they had female mentors; they may gravitate toward other subspecialties because of the greater visibility and encouragement of female peers in those fields. Woodward et al observed that PDs were more likely to be female if their division chief was also female [34]. Thus, until a critical mass of female mentors is reached, female trainees may opt for alternative career options, or may not be selected at all. Other researchers have identified structural and cultural features elsewhere in academia that can dissuade women and people of color from entering scientific careers [32,35], including but not limited to sexual harassment and historical "gender responsibilities" [36,37].

We call upon our peers, not just in GI, but also in other areas of medical education and clinical training, to be conscious of the underrepresentation of women, not only amongst their trainees and students, but also among their leadership ranks and advanced endoscopy. Without equality in mentorship and representation in leadership, groups that are historically disadvantaged will continue to struggle for recognition, research funding, networking and promotions, and newer generations of trainees will fall into the same cycle [38]. Though improvements in sex representation are evident among younger GI physicians in our study, the gaps in representation and bibliometric measures persist and underscore how much work is left to be done. Issues including the equal salaries and consistent parental leave policies are likewise areas that can help dismantle perceptions of unfair treatment and gender hostility.

Our own study has its shortcomings: for instance, it drew upon data sources such as program websites to identify chairs, chiefs and subspecialties, but websites are not necessarily updated or standardized for all programs. We sought to mitigate this by collecting data over a short period in early 2018 then updating everything in early 2019 , but the program websites were not necessarily changed in the interim. Moreover, the h-index and number of publications measure one aspect of academic achievement and cannot account for those whose career goals involve educational and scholarly activities outside of writing research papers. We used these measures since they are objective and commonly used when considering promotions in academia, but they nonetheless remain an imperfect reflection of an individual's scholarly contributions. Our study did not look at non-academic GI positions, such as in community practices, so this is a potential area for research into sex representation in leadership positions and possible inequalities in work-related experiences.

In conclusion, sex disparities persist in academic GI with regard to leadership positions, GI subspecialties, and scholarly productivity as measured by h-indices. The lower h-indices, among other various structural obstacles, can in turn prevent more women from progressing to leadership positions, thereby exacerbating underrepresentation.

\section{Summary Box}

\section{What is already known:}

- Publication history is a key factor in securing academic promotions

- Women have been historically underrepresented in gastroenterology, but their numbers have been rising in recent years

- Recent studies suggest that women have achieved equal publication productivity with men in academic gastroenterology

\section{What the new findings are:}

- Women remain largely underrepresented in departmental, divisional, and fellowship program leadership positions, as well as at all faculty and trainee levels

- Women have narrowed the gap in publication metrics with men, though disparities in leadership representation and publications persist and may be due to the historical underrepresentation and ongoing lack of mentorship and support compared to men

- Certain subspecialties within gastroenterology, in particular advanced endoscopy, have significant underrepresentation of women among faculty, which may discourage women from pursuing careers in these fields

\section{References}

1. Jagsi R, Tarbell NJ, Henault LE, Chang Y, Hylek EM. The representation of women on the editorial boards of major medical journals: a 35-year perspective. Arch Intern Med 2008;168:544-548.

2. Jagsi R, Guancial EA, Worobey CC, et al. The "gender gap" in authorship of academic medical literature-a 35-year perspective. N Engl J Med 2006;355:281-287.

3. Sun GH, Moloci NM, Schmidt K, Maceachern MP, Jagsi R. Representation of women as authors of collaborative cancer clinical trials. JAMA Intern Med 2014;174:806-808.

4. Patton EW, Griffith KA, Jones RD, Stewart A, Ubel PA, Jagsi R. Differences in mentor-mentee sponsorship in male vs female recipients of National Institutes of Health grants. JAMA Intern Med 2017; 177:580-582.

5. Jagsi R, Griffith KA, Stewart A, Sambuco D, DeCastro R, Ubel PA. Gender differences in the salaries of physician researchers. JAMA 2012;307:2410-2417.

6. Raj A, Carr PL, Kaplan SE, Terrin N, Breeze JL, Freund KM. Longitudinal analysis of gender differences in academic productivity among medical faculty across 24 medical schools in the United States. Acad Med 2016;91:1074-1079.

7. Saleem T. The Hirsch Index - a play on numbers or a true appraisal of academic output? Int Arch Med 2011;4:25.

8. Sharma B, Boet S, Grantcharov T, Shin E, Barrowman NJ, Bould MD. The H-Index outperforms other bibliometrics in the 
assessment of research performance in general surgery: a provincewide study. Surgery 2013;153:493-501.

9. https://Www.Census.Gov/Geo/Pdfs/Maps-Data/Maps/Reference/ Us_Regdiv.Pdf. 2010.

10. Bakkalbasi N, Bauer K, Glover J, Wang L. Three options for citation tracking: Google Scholar, Scopus and Web of Science. Biomed Digit Libr 2006;3:7.

11. Sethi S, Mendoza S, Webb A, Mendoza S, Kumar A, Chae S. Addressing gender disparity: increase in female fellowship program leadership increases gender equality in program director and fellow ranks. Dig Dis Sci 2021 Jan 6 [Epub ahead of print]. doi: 10.1007/s10620-020-06686-5

12. Schwartz J, Karnik N, Ahmad AS. 211-female Gi leaders: mentorship, promotion, and gender disparities in the workplace. Gastrointest Endosc 2019;89:AB62.

13. Rabinowitz LG, Anandasabapathy S, Sethi A, Siddiqui UD, Wallace MB, Kim MK. Addressing gender in gastroenterology: opportunities for change. Gastrointest Endosc 2020;91:155-161.

14. Carr PL, Raj A, Kaplan SE, Terrin N, Breeze JL, Freund KM. Gender differences in academic medicine: retention, rank, and leadership comparisons from the National Faculty Survey. Acad Med 2018;93:1694-1699.

15. Enestvedt BK, Diamond S, Laird A, Rodriguez SA. A gender comparison of motivations for seeking leadership positions among gastroenterologists. Gastrointest Endosc 2020;91:26-32.

16. Jagsi R, Griffith KA, Stewart A, Sambuco D, DeCastro R, Ubel PA. Gender differences in salary in a recent cohort of early-career physician-researchers. Acad Med 2013;88:1689-1699.

17. Calderwood AH, Enestvedt BK, DeVivo R, Schmitt CM. Impact of gender on requests for ASGE leadership assignments. Gastrointest Endosc 2016;83:730-733.

18. Holliday E, Griffith KA, De Castro R, Stewart A, Ubel P, Jagsi R. Gender differences in resources and negotiation among highly motivated physician-scientists. J Gen Intern Med 2015;30:401-407.

19. Long MT, Leszczynski A, Thompson KD, Wasan SK, Calderwood AH. Female authorship in major academic gastroenterology journals: a look over 20 years. Gastrointest Endosc 2015;81:1440-1447.

20. Enestvedt BK, DeVivo RS, Schmitt CM, Calderwood AH. Increase in female faculty in American Society for Gastrointestinal Endoscopy-sponsored programming over time. Gastrointest Endosc 2018;87:952-955.

21. Pascua M, Kushner T, Woodward Z. Promoting leadership by women in gastroenterology-lessons learned and future directions. Gastroenterology 2019;156:1548-1552.

22. Eloy JA, Svider PF, Cherla DV, et al. Gender disparities in research productivity among 9952 academic physicians. Laryngoscope 2013;123:1865-1875.

23. Ahmed AA, Hwang WT, Holliday EB, et al. Female representation in the academic oncology physician workforce: radiation oncology losing ground to hematology oncology. Int J Radiat Oncol Biol Phys 2017;98:31-33.

24. Desai T, Ali S, Fang X, Thompson W, Jawa P, Vachharajani T. Equal work for unequal pay: the gender reimbursement gap for healthcare providers in the United States. Postgrad Med J 2016;92:571-575.

25. Elta GH. The challenges of being a female gastroenterologist. Gastroenterol Clin North Am 2011;40:441-447, ix-x.

26. Edmunds LD, Ovseiko PV, Shepperd S, et al. Why do women choose or reject careers in academic medicine? A narrative review of empirical evidence. Lancet 2016;388:2948-2958.

27. Jagsi R, Motomura AR, Griffith KA, Rangarajan S, Ubel PA. Sex differences in attainment of independent funding by career development awardees. Ann Intern Med 2009;151:804-811.

28. DeCastro R, Griffith KA, Ubel PA, Stewart A, Jagsi R. Mentoring and the career satisfaction of male and female academic medical faculty. Acad Med 2014;89:301-311.

29. Freund KM, Raj A, Kaplan SE, et al. Inequities in academic compensation by gender: a follow-up to the National Faculty Survey Cohort Study. Acad Med 2016;91:1068-1073.

30. Jolly S, Griffith KA, DeCastro R, Stewart A, Ubel P, Jagsi R. Gender differences in time spent on parenting and domestic responsibilities by high-achieving young physician-researchers. Ann Intern Med 2014; 160:344-353.

31. Van Niel MS, Bhatia R, Riano NS, et al. The impact of paid maternity leave on the mental and physical health of mothers and children: a review of the literature and policy implications. Harv Rev Psychiatry 2020;28:113-126.

32. Ginther DK, Kahn S, Schaffer WT. Gender, Race/Ethnicity, and National Institutes of Health R01 Research Awards: is there evidence of a double bind for women of color? Acad Med 2016;91:1098-1107.

33. Jagsi R, DeCastro R, Griffith KA, et al. Similarities and differences in the career trajectories of male and female career development award recipients. Acad Med 2011;86:1415-1421.

34. Woodward Z, Rodriguez Z, Jou JH, et al. Gender disparities in gastroenterology fellowship director positions in the United States. Gastrointest Endosc 2017;86:595-599.

35. Rainey K, Dancy M, Mickelson R, Stearns E, Moller S. Race and gender differences in how sense of belonging influences decisions to major in STEM. Int J STEM Educ 2018;5:10.

36. Feliu-Dominguez R, Medero-Rodriguez P, Cruz-Correa M. Women gastroenterologists in academic medicine: tradition versus transition. Dig Dis Sci 2017;62:13-15.

37. Jagsi R. Sexual Harassment in Medicine - \#MeToo. N Engl J Med 2018;378:209-211.

38. Jagsi R, Jones RD, Griffith KA, et al. An innovative program to support gender equity and success in academic medicine: early experiences from the Doris Duke Charitable Foundation's fund to retain clinical scientists. Ann Intern Med 2018;169:128-130. 